\title{
Global Distribution of the Phase State and Mixing Times Within Secondary Organic Aerosol Particles in the Troposphere Based on Room-Temperature Viscosity Measurements
}

Adrian M. Maclean ${ }^{1}$, Ying Li ${ }^{2, a}$, Giuseppe V. Crescenzo ${ }^{1}$, Natalie R. Smith ${ }^{2}$, Vlassis A. Karydis ${ }^{3}$, Alexandra P. Tsimpidi ${ }^{3,4}$, Christopher L. Butenhoff ${ }^{5}$, Celia L. Faiola ${ }^{2,6}$, Jos Lelieveld ${ }^{7,8}$, Sergey A. Nizkorodov $^{2}$, Manabu Shiraiwa ${ }^{2}$, Allan K. Bertram ${ }^{1 *}$

${ }^{1}$ Department of Chemistry, University of British Columbia, Vancouver, BC, V6T 1Z1, Canada

${ }^{2}$ Department of Chemistry, University of California Irvine, Irvine, CA 92697, USA

${ }^{3}$ Institute of Energy \& Climate Research, IEK-8: Troposphere, Forschungszentrum Jülich GmbH, 52428 Jülich, Germany

${ }^{4}$ Institute for Environmental Research \& Sustainable Development, National Observatory of Athens, 15236 Palea Penteli, Greece

${ }^{5}$ Dept. of Physics, Portland State University, Portland, Oregon, 97201, USA

${ }^{6}$ Department of Ecology and Evolutionary Biology, University of California Irvine, Irvine, CA, 92697, USA

${ }^{7}$ Atmospheric Chemistry Department, Max Planck Institute for Chemistry, 55128 Mainz, German ${ }^{8}$ Energy, Environment and Water Research Center, The Cyprus Institute, Nicosia 1645, Cyprus

a now at: Institute of Atmospheric Physics, Chinese Academy of Sciences, Beijing, 100029, China

*Correspondence to: Allan K. Bertram (bertram@chem.ubc.ca)

\section{S1 Viscosity measurements of Scots pine tree SOA at 59 and $74 \% \mathrm{RH}$ using the poke-flow technique.}

Recently, Smith et al. ${ }^{1}$ reported the viscosity of SOA generated from the photooxidation of a mixture of volatile organic compounds used to represent the emissions from healthy Scots pine trees. Viscosities were determined using the poke-flow technique at relative humidity $(\mathrm{RH})$ values $<50 \%$. Here we add to these measurements by carrying out similar measurements, but at RH values of 59 and $74 \%$. The same procedure was used to measure the viscosity and the same conditions were used to generate the SOA. For details of SOA generation see Smith et al. ${ }^{1}$.

The poke-flow technique has been described previously. ${ }^{2-4}$ The SOA is collected on a hydrophobic glass slide (coated with FluorPel 800, Cytonix) using an impactor as described in Smith et al. ${ }^{1}$ After collection, the SOA particles on the slides were $30-80 \mu \mathrm{m}$ in diameter. The glass slide is placed in a humidity-controlled flow cell, and humidified nitrogen is passed through the cell to condition the particles to the surrounding RH. After conditioning the particles, a needle (13561-20, Ted Pella Inc.) is attached to a micromanipulator and used to poke the particles, leaving the particles in a half-torus geometry. After poking, the material flows to return to the spherical cap geometry, and images are recorded as it flows. From the images, the experimental flow time, $\tau_{\text {flow, exp }}$, is determined, which is defined as the time it takes for the area of the hole to reduce to a quarter of its original size. Viscosity is then determined using fluid simulations in COMSOL Multiphysics. A half-torus is generated in COMSOL using the particle and hole dimensions from the experiments. Literature values for material properties of surface tension, density, slip length, and contact angle are 
used as inputs (see Table S2 in Smith et al. ${ }^{1}$ ). The model also uses viscosity as an input, and the particle viscosity is determined by varying the input viscosity until the area of the hole in the model reduces to a quarter of its original size for the experimental time.

The time used to condition the particles to the surrounding $\mathrm{RH}$ prior to poking was $1.5-24.0 \mathrm{~h}$ and $3.8 \mathrm{~h}$, for $\mathrm{RH}$ values of 59 and $74 \%$, respectively (Table S1). To determine if this time was sufficient for near equilibrium conditions, we first calculated the diffusion coefficients of water within the particles from the measured viscosity and using the fractional Stokes-Einstein equation (eq 10 and 11 in the main text). To evaluate eq 11 we assumed $R_{\text {diff }}=0.1 \mathrm{~nm}$ and

$R_{\text {matrix }}=0.4 \mathrm{~nm}$, as discussed in the main text, where $R_{\text {diff }}$ is the radius of water molecules, and $R_{\text {matrix }}$ is the radius of the organic molecules in the SOA. Once the diffusion coefficients of water were calculated, we next calculated the characteristic mixing time of water within the particles using eq 9 in the main text. Based on these calculations, the characteristic mixing times of water were always shorter than the experimental conditioning times used in the experiments, indicating that near equilibrium conditions were reached (Table S1).

\section{S2 Viscosity of Scots pine tree SOA at 75,85 , and $95 \%$ RH based on diffusion measurements}

For Scots pine tree SOA, the poke flow technique was limited to RH values $<75 \%$. At higher RH values the material flowed too fast for the poke-flow measurements. To determine viscosities of Scots pine tree SOA at higher RH values $(75,85$, and $95 \% \mathrm{RH})$, we first measured diffusion coefficients of large fluorescent organic molecules within the Scots pine tree SOA using rectangle area fluorescence recovery after photobleaching (rFRAP). The diffusion coefficients were then converted into viscosities using the Stokes-Einstein equation (eq 8 in the main text). The StokesEinstein equation together with measured diffusion coefficients should give accurate values of viscosities when the radii of the diffusing molecules are larger than the radii of the organic matrix molecules, ${ }^{5,6}$ which is the case in our experiments. The same procedure was used to generate the Scots pine tree SOA for the rFRAP measurements as described in Smith et al. ${ }^{1}$. The large fluorescent organic molecule used in the current study was rhodamine 6G (R6G), which has a molecular mass of $479.02 \mathrm{~g} / \mathrm{mol}$ and a radius of 0.589 nanometers. $^{7}$

The rFRAP technique is described in detail previously ${ }^{8}$ and has been used to measure the diffusion of fluorescent organic molecules in SOA ${ }^{9}$ and SOA proxies. ${ }^{5,6,10}$ For the rFRAP experiments, glass slides (Hampton Research, 12 $\mathrm{mm}$ circular slides) for sample collection were first prepared by submerging them in NoChromix for $24 \mathrm{~h}$, then washing the slides with methanol and water and putting them in an oven overnight. Slides were then coated with the fluorescent organic dye R6G by depositing $10 \mu \mathrm{L}$ of a $4 \mathrm{mM} \mathrm{R6G}$ solution in ethanol on the slide and spin-coating at 6100 RPM for 1 minute. SOA was then collected on the dye coated slides using an impactor as described in Smith et al. ${ }^{1}$. After collection, the slides containing SOA were placed into glass jars containing saturated salt solutions of either $\mathrm{NaCl}, \mathrm{KCl}$, or $\mathrm{KNO}_{3}$ to condition the sample to the $\mathrm{RH}$ of choice $(75,85$, and $95 \% \mathrm{RH}$, respectively). The samples at $75 \%$ and $85 \% \mathrm{RH}$ were conditioned for $24 \mathrm{~h}$ and the sample at $95 \%$ was conditioned for $48 \mathrm{~h}$. These conditioning times were more than enough to reach equilibrium between the SOA and the surrounding gas phase based on calculations similar to those described in Section S1. After the SOA reached equilibrium with the RH in the jar, the 
jar was put into a Glove Bag ${ }^{\mathrm{TM}}$ (Glas-Col). The RH in the Glove Bag was controlled using a flow of humidified nitrogen gas, and the RH was measured using a handheld hygrometer. The RH in the bag was set to the same RH as the jar. The sample was removed from the glass jar and a siliconized glass slide was placed on top (Hampton Research, $12 \mathrm{~mm}$ circular slides) causing the SOA particles to form thin films approximately 15-25 $\mu \mathrm{m}$ thick, determined with a confocal laser scanning microscope. The two circular glass slides were then sandwiched between two larger glass slides coated with vacuum grease along the edges (Figure S3) to ensure the RH within the sample did not change after it was removed from the glove bag. A metal spacer was included between the two sandwiched glass slides as well to ensure there was a large enough gap between the two slides for the smaller $12 \mathrm{~mm}$ slides (Figure S3).

The rFRAP experiments used a $543 \mathrm{~nm}$ helium-neon laser on a confocal laser scanning microscope to photobleach fluorescent molecules in a specified region of the thin film. Once a rectangular region of the sample was photobleached, the bleached molecules diffused out of the area and unbleached molecules diffused in causing the fluorescence in the bleached region to recover. The time dependence of the fluorescence recovery was monitored using the confocal laser scanning microscope. From the time dependent recovery, diffusion coefficients were determined.

The rFRAP experiments were performed using a Zeiss LSM510 confocal laser scanning microscope with a 10X objective, a numerical aperture of 0.3 , and a pinhole setting of $80 \mu \mathrm{m}$. The laser power used for bleaching was adjusted to obtain a bleach depth of $20-40 \%$. It has previously been reported that measured diffusion coefficients are independent of bleach depth up to a bleach depth of $50 \%$ for the rFRAP technique. ${ }^{8}$ The photobleaching areas ranged from $20 \mu \mathrm{m}^{2}$ to $324 \mu \mathrm{m}^{2}$, with the smaller areas being used at lower RHs, since lower RHs resulted in lower diffusion rates. After bleaching, the sample was scanned at time intervals ranging from 5-1200 seconds. The time intervals were varied based on the rate of recovery of the fluorescence in the bleached area. Heating of the film during the photobleaching process is not expected to impact the measured diffusion coefficients. While heating may occur, thermal diffusion would be much faster than the molecular diffusion, meaning the heat would be lost to the surroundings much more rapidly than the molecules would diffuse. ${ }^{10}$ This is consistent with previous measurements at different photobleaching sizes and powers. ${ }^{9,10}$

The fluorescence intensity after photobleaching can be described using the following equation ${ }^{8}$

$$
\frac{F(x, y, t)}{F_{0}(x, y)}=1-\frac{K_{0}}{4}\left[\operatorname{erf}\left(\frac{x+\frac{l_{x}}{2}}{\sqrt{r^{2}+4 D t}}\right)-\operatorname{erf}\left(\frac{x-\frac{l_{x}}{2}}{\sqrt{r^{2}+4 D t}}\right)\right] \times\left[\operatorname{erf}\left(\frac{y+\frac{l_{y}}{2}}{\sqrt{r^{2}+4 D t}}\right)-\operatorname{erf}\left(\frac{y-\frac{l_{y}}{2}}{\sqrt{r^{2}+4 D t}}\right)\right]
$$

where $F(x, y, t)$ is the fluorescence intensity at position $(x, y)$ at time $t$ after photobleaching; $F_{0}(x, y)$ is the initial fluorescence intensity at position $(\mathrm{x}, \mathrm{y})$ before photobleaching; $\mathrm{K}_{0}$ is the effective bleach depth, or the decrease in the fluorescence intensity in the photobleached area; $l_{y}$ and $l_{x}$ are the dimensions of the photobleached area; $r$ is the lateral resolution of the microscope; $\mathrm{D}$ is the diffusion coefficient of the fluorescent molecule; and erf is the error function.

After an rFRAP experiment, the images were first normalized to an image collected before photobleaching using ImageJ. ${ }^{11}$ The image resolution was reduced from $512 \times 512$ pixels to $128 \times 128$ pixels to reduce noise. Then each image was fit to eq S1 using a Matlab script (The Mathworks, Natick, MA, USA), with $K_{0}$ and $r^{2}+4 D t$ as free parameters. The bleach width $\left(1_{\mathrm{x}}\right.$ and $\left.\mathrm{l}_{\mathrm{y}}\right)$ was determined by fitting eq $\mathrm{S} 1$ to the first five images after photobleaching 
with the bleach width left as a free parameter. The value of the bleach width was then used as an input when analysing all the images. A value for $\mathrm{r}^{2}+4 \mathrm{Dt}$ was obtained from each image and was plotted as a function of time after photobleaching. The data was fit to a straight line, and the diffusion coefficient was determined from the slope of the line. An example of an $\mathrm{r}^{2}+4 \mathrm{Dt}$ plot is shown in Figure S4. Images were only used if the signal was less than 3 times the standard deviation of the noise.

Equation S1 assumes that there is no diffusion in the $\mathrm{z}$ direction. It has been shown that eq S1 gives accurate diffusion coefficients when the thickness of the film is $\leq 120 \mu \mathrm{m}$ and the numerical aperture of the microscope is $\leq$ $0.45,{ }^{8}$ which is the case in our experiments.

\section{S3 Activity based viscosity mixing rule}

The activity based mixing rule is based on the Arrhenius mixing rule

$$
\log \left(\eta_{\text {mix }}\right)=x_{S O A} \log \left(\eta_{S O A}\right)+x_{H 2 O} \log \left(\eta_{H 2 O}\right)(\mathrm{S} 2)
$$

where $\eta_{\text {mix }}, \eta_{\mathrm{SOA}}$ and $\eta_{\mathrm{H} 2 \mathrm{O}}$ are the viscosity of the mixture, SOA, and water, respectively, and $x_{\mathrm{SOA}}$ and $x_{\mathrm{H} 2 \mathrm{O}}$ are the mole fraction of the SOA and water in the mixture. The mole fraction of water and SOA can be calculated from the RH using the following equation ${ }^{12}$

$$
a_{w}=\frac{1}{\left(1+i_{\mathrm{SOA}} \frac{n_{\mathrm{SOA}}}{n_{\mathrm{H} 2 \mathrm{O}}}\right)}(\mathrm{S} 3)
$$

where $a_{\mathrm{w}}$ is the activity of water, $i$ is the van't Hoff factor, and $n_{\mathrm{SOA}}$ and $n_{\mathrm{H} 2 \mathrm{O}}$ are the moles of water and SOA, respectively. We assumed a van't Hoff factor of 1 . This allows the equation to be rearranged into the form:

$$
a_{w}=\frac{n_{\mathrm{H} 2 \mathrm{O}}}{\left(n_{\mathrm{H} 2 \mathrm{O}}+n_{\mathrm{SOA}}\right)}(\mathrm{S} 4)
$$

This equation shows that the mole fraction of water is equal to the activity of water in an ideal solution with a van't Hoff factor of 1 . The activity of water is defined as $\frac{R H}{100}$, which can be combine with equation S2 to give the final activity based mixing rule

$$
\log (\eta)=\left(1-\frac{R H}{100}\right) \log \left(\eta_{S O A}\right)+\frac{R H}{100} \log \left(\eta_{H 2 O}\right)(\mathrm{S} 5)
$$

\section{S4 Viscosity of water as a function of temperature}

The viscosity of water as a function of temperature was determined based on the temperature-dependent viscosities between $311 \mathrm{~K}$ and $230 \mathrm{~K}$ from Hallett ${ }^{13}$ and Crittenden et al. ${ }^{14}$ (Figure S5). The data was fit to the VTF equation $^{15}$

$$
\log (\eta)=A+\frac{B}{\left(T-T_{0}\right)}(\mathrm{S} 6)
$$

where $A$ and $B$ are fitting constants. The VTF equation is an empirical equation that has been used to fit temperaturedependence viscosity data for a wide variety of compounds..$^{15}$ The values of $\left[A, B\right.$, and $\left.T_{0}\right]$ obtained from the fitting were $[-4.28 \pm 0.011,152.87 \pm 2.21,173.06 \pm 0.70]$, respectively. The fit to the data is shown in Figure S5 as a solid line. 


\section{Tables and Figures}

Table S1: Relevant experimental conditions used in the poke-flow experiments. RH is the relative humidity at which the experiments were carried out. The midpoint of viscosity is based on the poke-flow measurements. The diffusion coefficient of water was calculated from the viscosity and the fractional Stokes-Einstein equation. The $d_{p}$ values listed here are the diameter of the droplets used in the poke-flow experiments. These $d_{p}$ values are different than the $d_{p}$ value used when calculating mixing times in SOA in the atmosphere (see main text). For the latter we used a $d_{p}$ value of $200 \mathrm{~nm}$, which corresponds to a common size of SOA particles in the atmosphere. The $\tau_{\text {mix,H2O values are the calculated }}$ characteristic mixing time of water within the particles based on the calculated diffusion coefficients of water. The

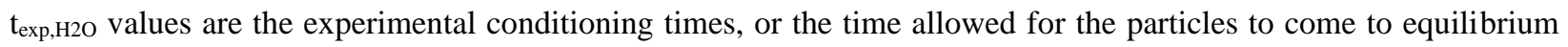
with the surrounding RH.

\begin{tabular}{|c|c|c|c|c|c|}
\hline RH (\%) & $\begin{array}{c}\text { Midpoint of } \\
\text { viscosity }(\mathrm{Pa} \\
\mathrm{s})\end{array}$ & $\begin{array}{c}\text { Diffusion } \\
\text { coefficient of } \\
\text { water }\left(\mathrm{m}^{2} \mathrm{~s}^{-1}\right)\end{array}$ & $\mathrm{d}_{\mathrm{p}}(\mu \mathrm{m})$ & $\tau_{\text {mix,H2O }}(\mathrm{hrs})$ & $\mathrm{t}_{\text {exp,H2O }}(\mathrm{hrs})$ \\
\hline 59 & $2 \times 10^{4}$ & $3 \times 10^{-13}$ & $55-59$ & $0.08-0.09$ & $1.5-24$ \\
\hline 74 & $1 \times 10^{3}$ & $1 \times 10^{-12}$ & $58-67$ & $0.017-0.023$ & 3.75 \\
\hline
\end{tabular}
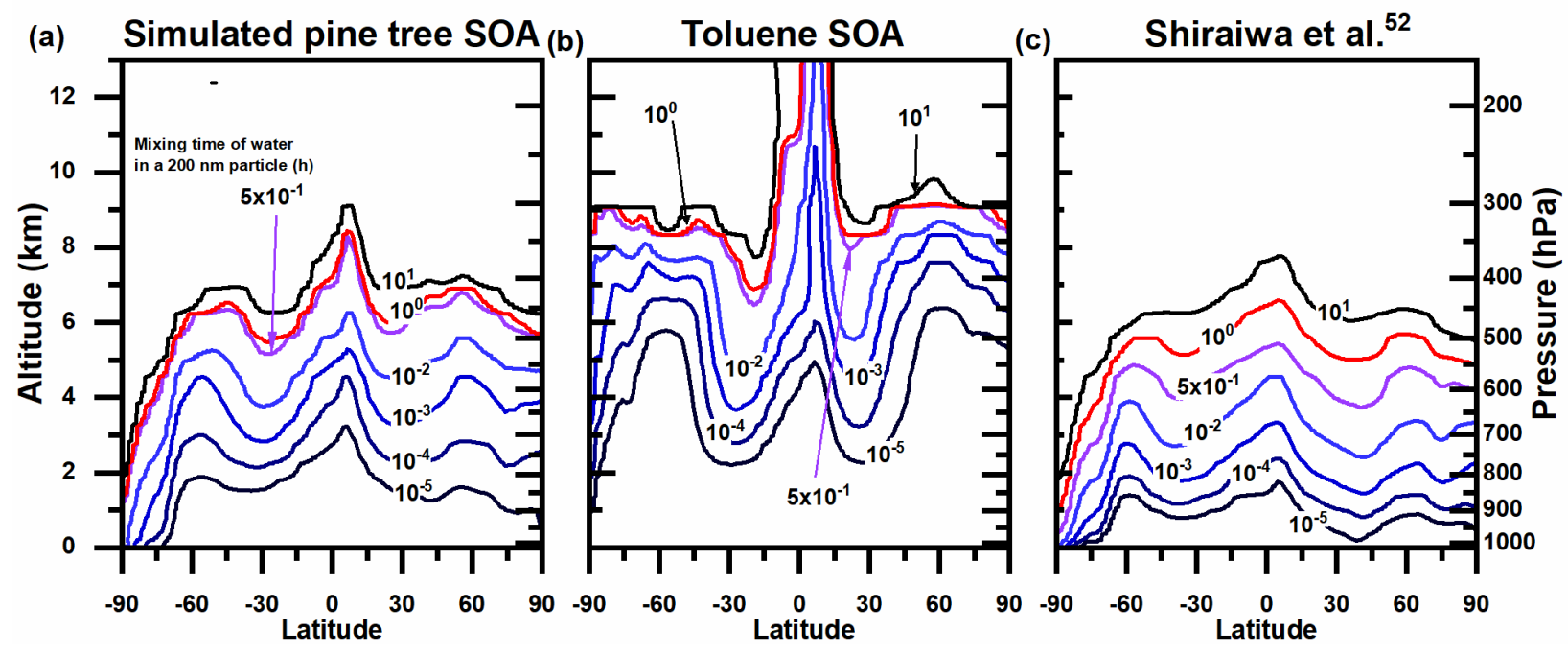

Figure S1. Annual average mixing time of water in a $200 \mathrm{~nm}$ particle for (a) simulated pine tree SOA, (b) toluene SOA, and (c) SOA from Shiraiwa et al. ${ }^{52}$ as a function of altitude and latitude. The contour lines correspond to mixing 
times in hours. The red contour line corresponds to a mixing time of $1 \mathrm{~h}$ and the purple contour line corresponds to a mixing time of $0.5 \mathrm{~h}$.
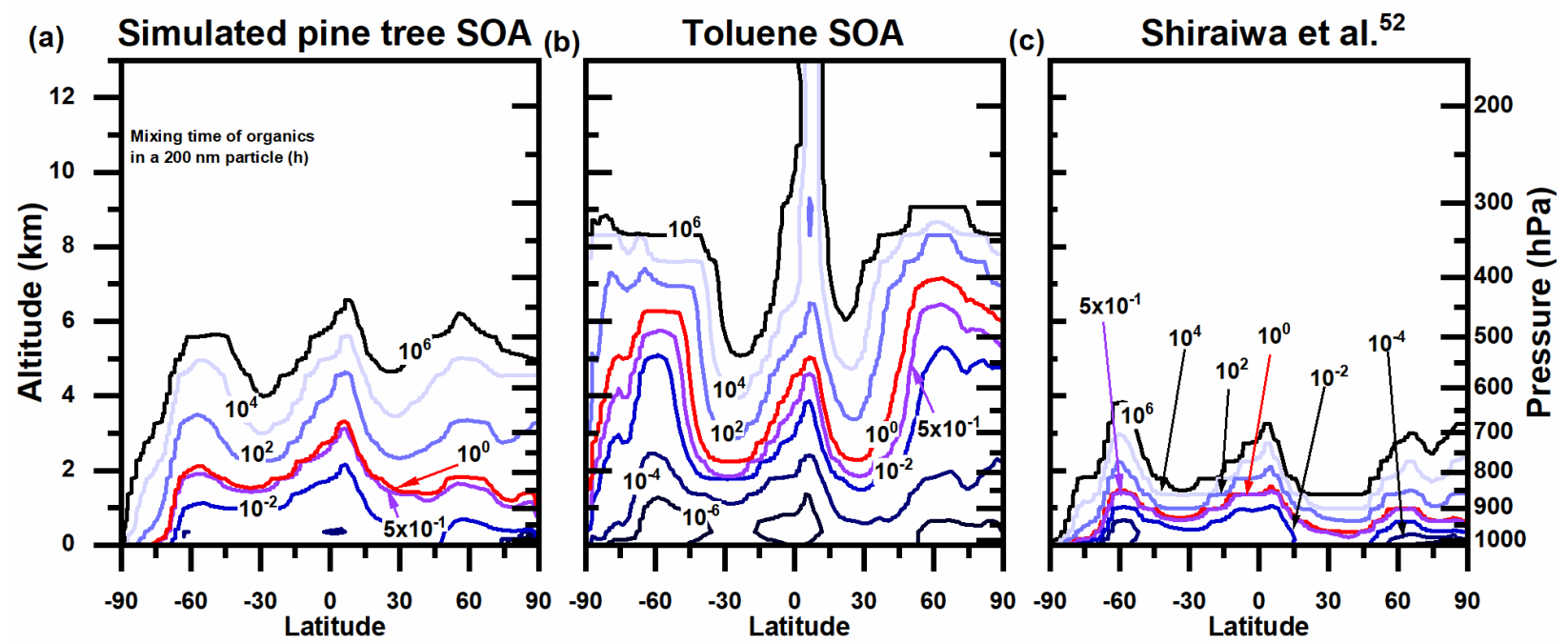

Figure S2. Annual average mixing time of organic molecules within SOA for (a) simulated pine tree SOA, (b) toluene SOA, and (c) SOA from Shiraiwa et al. ${ }^{52}$ as a function of altitude and latitude. The contour lines correspond to mixing times in hours. The red contour line corresponds to a mixing time of $1 \mathrm{~h}$ and the purple contour line corresponds to a mixing time of $0.5 \mathrm{~h}$. 
(a)

Fluorescent SOA films,

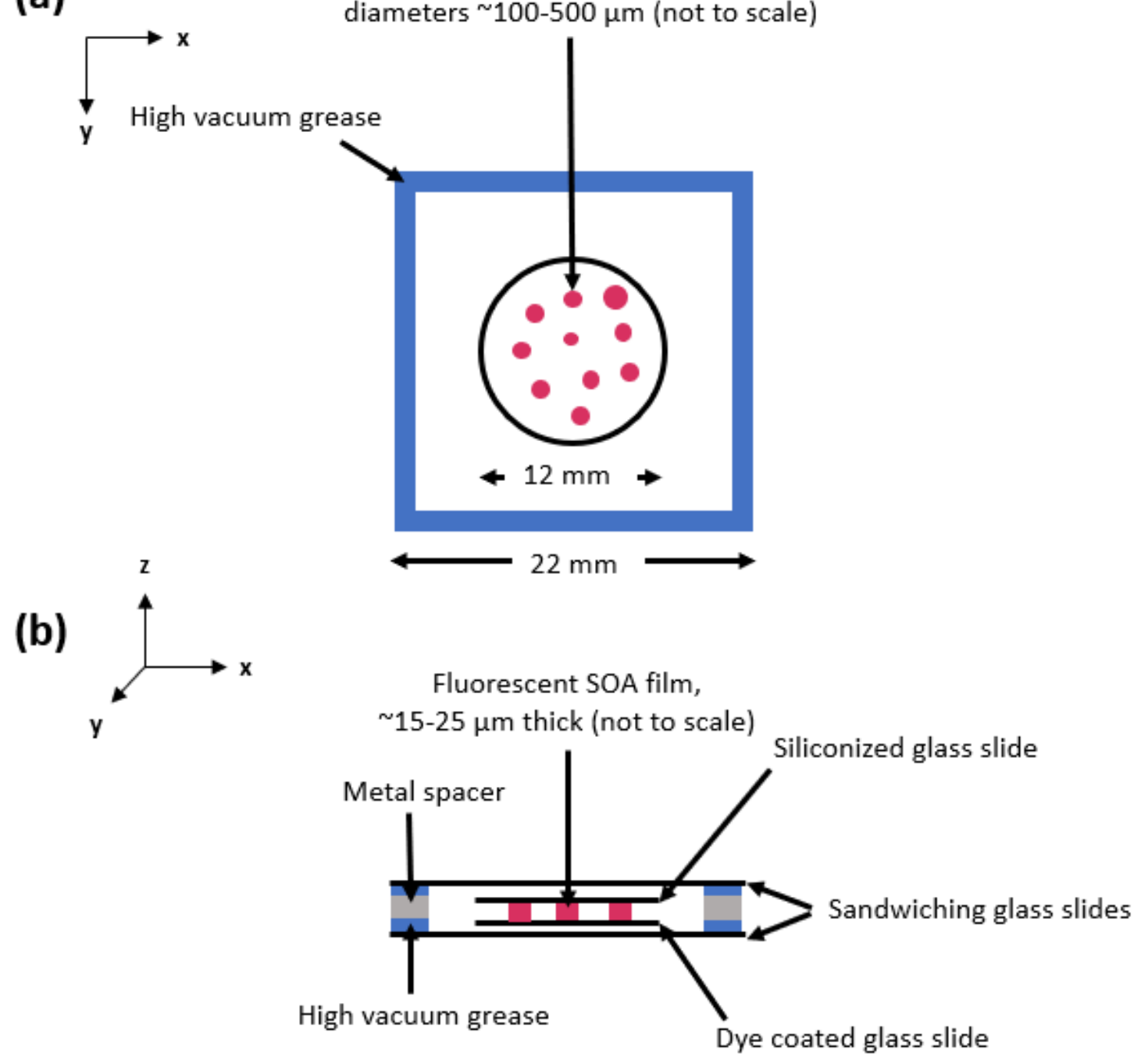

Figure S3. Schematic of a prepared rFRAP sample. Panel (a) shows a top view and panel (b) shows a side view of the prepared sample. 


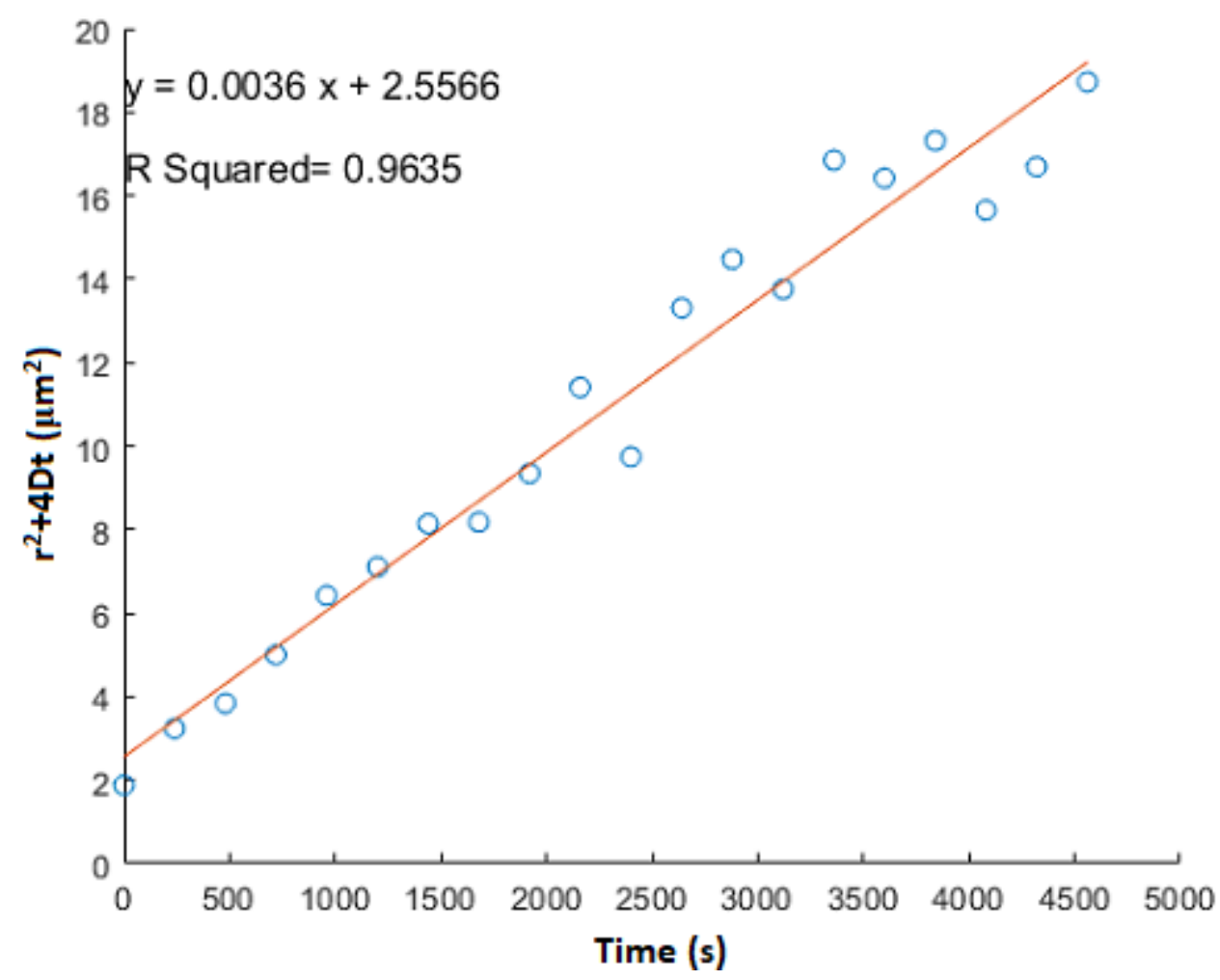

Figure S4. Plot of $\mathrm{r}^{2}+4 \mathrm{Dt}$ as a function of time after a SOA sample containing a fluorescent organic dye (Rhodamine $6 \mathrm{G})$ was photobleached at an $\mathrm{RH}$ of $85 \%$. Each circle corresponds to a value obtained from the fit of eq S1 to one of the images recorded after photobleaching and the red line corresponds to the linear best fit to the data. 


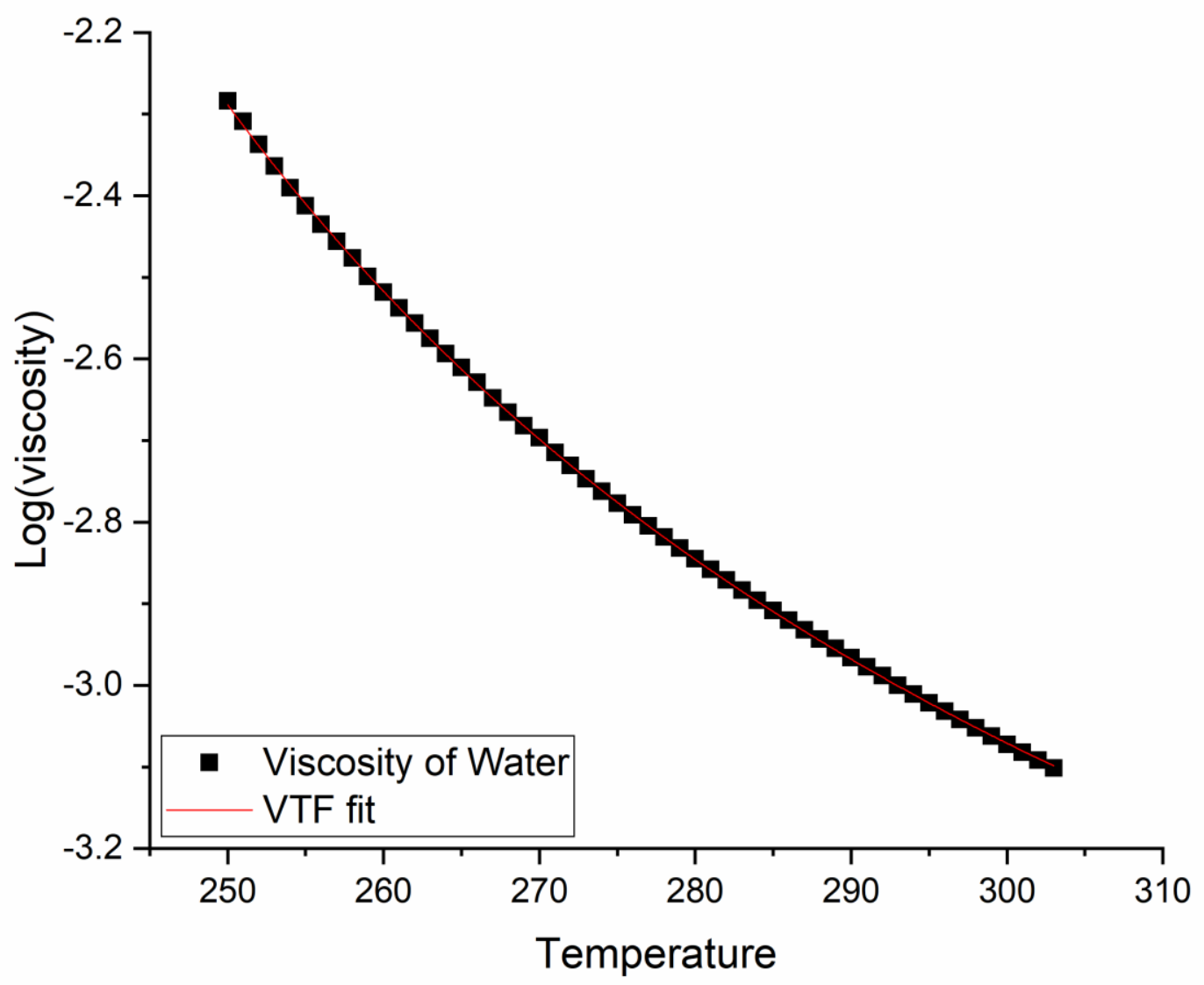

Figure S5. Viscosity as a function of temperature for water and fit to the experimental data using the VTF equation. The black squares correspond to the measured viscosities of water as a function of temperature from Hallett ${ }^{13}$ and Crittenden et al. ${ }^{14}$ and the red line is a fit to the data using the VTF equation (eq S6). 


\section{References}

(1) Smith, N. R.; Crescenzo, G. V.; Huang, Y.; Hettiyadura, A. P. S.; Siemens, K.; Li, Y.; Faiola, C. L.; Laskin, A.; Shiraiwa, M.; Bertram, A. K.; Nizkorodov, S. A. Viscosity and Liquid-Liquid Phase Separation in Healthy and Stressed Plant SOA. Environ. Sci. Atmos. 2021, 1 (3), 140-153. https://doi.org/10.1039/d0ea00020e.

(2) Grayson, J. W.; Song, M.; Sellier, M.; Bertram, A. K. Validation of the Poke-Flow Technique Combined with Simulations of Fluid Flow for Determining Viscosities in Samples with Small Volumes and High Viscosities. Atmos. Meas. Tech. 2015, 8 (6), 2463-2472. https://doi.org/10.5194/amt-8-2463-2015.

(3) Grayson, J. W.; Zhang, Y.; Mutzel, A.; Renbaum-Wolff, L.; Böge, O.; Kamal, S.; Herrmann, H.; Martin, S. T.; Bertram, A. K. Effect of Varying Experimental Conditions on the Viscosity of $\alpha$-Pinene Derived Secondary Organic Material. Atmos. Chem. Phys. 2016, 16 (10), 6027-6040. https://doi.org/10.5194/acp-166027-2016.

(4) Renbaum-Wolff, L.; Grayson, J. W.; Bateman, A. P.; Kuwata, M.; Sellier, M.; Murray, B. J.; Shilling, J. E.; Martin, S. T.; Bertram, A. K. Viscosity of $\alpha$-Pinene Secondary Organic Material and Implications for Particle Growth and Reactivity. Proc. Natl. Acad. Sci. U. S. A. 2013, 110 (20), 8014-8019. https://doi.org/10.1073/pnas.1219548110.

(5) Evoy, E.; Kamal, S.; Patey, G. N.; Martin, S. T.; Bertram, A. K. Unified Description of Diffusion Coefficients from Small to Large Molecules in Organic-Water Mixtures. J. Phys. Chem. A 2020, 124 (11), 2301-2308. https://doi.org/10.1021/acs.jpca.9b11271.

(6) Evoy, E.; Maclean, A. M.; Rovelli, G.; Li, Y.; Tsimpidi, A. P.; Karydis, V. A.; Kamal, S.; Lelieveld, J.; Shiraiwa, M.; Reid, J. P.; Bertram, A. K. Predictions of Diffusion Rates of Large Organic Molecules in Secondary Organic Aerosols Using the Stokes-Einstein and Fractional Stokes-Einstein Relations. Atmos. Chem. Phys. 2019, 19 (15), 10073-10085. https://doi.org/10.5194/acp-19-10073-2019.

(7) Müller, C. B.; Loman, A.; Pacheco, V.; Koberling, F.; Willbold, D.; Richtering, W.; Enderlein, J. Precise Measurement of Diffusion by Multi-Color Dual-Focus Fluorescence Correlation Spectroscopy. EPL 2008, 80 (4), 46001.

(8) Deschout, H.; Hagman, J.; Fransson, S.; Jonasson, J.; Rudemo, M.; Loren, N.; Braeckmans, K. Straightforward FRAP for Quantitative Diffusion Measurements with a Laser Scanning Microscope. Opt. Express 2010, 18 (22), 22886-22905. https://doi.org/10.1364/oe.18.022886.

(9) Ullmann, D. A.; Hinks, M. L.; Maclean, A. M.; Butenhoff, C. L.; Grayson, J. W.; Barsanti, K.; Jimenez, J. L.; Nizkorodov, S. A.; Kamal, S.; Bertram, A. K. Viscosities, Diffusion Coefficients, and Mixing Times of Intrinsic Fluorescent Organic Molecules in Brown Limonene Secondary Organic Aerosol and Tests of the Stokes-Einstein Equation. Atmos. Chem. Phys. 2019, 19 (3), 1491-1503. https://doi.org/10.5194/acp-191491-2019.

(10) Chenyakin, Y.; Ullmann, D. A.; Evoy, E.; Renbaum-Wolff, L.; Kamal, S.; Bertram, A. K. Diffusion Coefficients of Organic Molecules in Sucrose-Water Solutions and Comparison with Stokes-Einstein Predictions. Atmos. Chem. Phys. 2017, 17 (3), 2423-2435. https://doi.org/10.5194/acp-2016-740.

(11) Schneider, C. A.; Rasband, W. S.; Eliceiri, K. W. NIH Image to ImageJ: 25 Years of Image Analysis. Nat. 
Methods 2012, 9 (7), 671-675. https://doi.org/10.1007/978-1-84882-087-6_9.

(12) Koop, T.; Bookhold, J.; Shiraiwa, M.; Pöschl, U. Glass Transition and Phase State of Organic Compounds: Dependency on Molecular Properties and Implications for Secondary Organic Aerosols in the Atmosphere. Phys. Chem. Chem. Phys. 2011, 13 (43), 19238-19255. https://doi.org/10.1039/c1cp22617g.

(13) Hallett, J. The Temperature Dependence of the Viscosity of Supercooled Water. Proc. Phys. Soc. 1963, 82 (6), 1046-1050. https://doi.org/10.1088/0370-1328/82/6/326.

(14) Crittenden, J. C.; Trussel, R. R.; Hand, D. W.; Howe, K. J.; Tchobanoglous, G. MWH's Water Treatment; John Wiley and Sons, 2012.

(15) Angell, C. A. Relaxation in Liquids, Polymers and Plastic Crystals - Strong/Fragile Patterns and Problems. J. Non. Cryst. Solids 1991, 133, 13-31. 